\title{
TEENAGE DRIVERS PORTABLE ELECTRONIC DEVICE USE WHILE DRIVING
}

\author{
Johnathon Ehsani, Kaigang Li \& Bruce G. Simons-Morton \\ National Institutes of Health, Bethesda, MD USA \\ johnathon.ehsani@nih.gov, kaigang.li@nih.gov, and mortonb@mail.nih.gov
}

\begin{abstract}
Summary: Young drivers' crash risk increases when they engage in certain secondary tasks while driving. Using a sample of participants from the NEXT Generation Health Study who reported having an independent driving license and driving at least one day in the last 30 days $(n=1,243)$, the prevalence of portable electronic device use while driving was estimated. Two measures of prevalence were calculated: (1) engaging in the behavior at least once in the last 30 days; (2) percentage of days engaged in the behavior, relative to the number of days driven in the last 30 days. A total of $82.84 \%$ reported engaging in electronic device use while driving at least once in the last 30 days. Specifically, $71.13 \%$ made or answered a phone call, $64.84 \%$ read or sent a text message, $20.29 \%$ read or sent an email, $29.11 \%$ checked a website, $71.64 \%$ changed music, $12.80 \%$ used a tablet or computer, and 52.64\% looked at directions or a map. Young drivers reported using electronic devices while driving on $19.06 \%$ of the days they drove. Males were more likely to use tablet or computer while driving, teens from moderate and high affluence households were more likely to check websites, and rural participants were less likely to look at directions or a map than urban participants. The number of days participants reported driving in the last 30 days, but not self-reported miles driven, was associated with a higher likelihood of using an electronic device while driving.
\end{abstract}

\section{INTRODUCTION}

Distraction poses a distinct safety risk to teenage drivers. In $2008,16 \%$ of all distraction-related fatal crashes in the United States were attributed to drivers below 20 years of age; the highest proportion for any age group (Governors Highway Safety Association 2010). Relative to experienced adult drivers, young drivers are more willing to engage in cell phone use while driving (Young and Lenne 2010, Tison, Chaudhary et al. 2011). Secondary tasks that take the driver's eyes off the forward roadway, including phone answering and dialing, texting, and emailing, increase crash risk (Klauer, Guo et al. 2014).

Previous studies of teenage drivers' cell phone use suggest the behavior is prevalent and normative. O'Brien, Goodwin, \& Foss (2014) found that approximately four-fifths of novice drivers reported ever talking on a cell phone while driving (O'Brien, Goodwin et al. 2010). Another distracted driving study found $47 \%$ of drivers aged 18 or older had ever sent or read a text message while driving, and $75 \%$ reported talking on the phone while driving (Madden and Raine 2010). The high prevalence of cell phone-related secondary task engagement suggests these behaviors may extend to other devices. However, little is known teenage drivers' use of other portable electronic devices while driving. The purpose of this study was to extend what is known about electronic-device related secondary task engagement among teenage drivers.

\section{METHODS}




\section{Sampling}

Data were from the fourth annual wave of a nationally representative cohort survey of high school students, the NEXT Generation Health study, which corresponded with the 2012-2013 academic year. The first wave of this cohort study began when students were in 10th grade. Students were sampled using a three-stage stratified cluster sample strategy, with school districts as the primary sampling unit. African American students were oversampled to improve the population estimate. Students completed questionnaires in the spring of the first year after high school, the age when most teenagers have obtained a license to drive independently. Students were given the opportunity to complete the survey online. If they were unable to do so, a research staff member provided participants with a hard copy. The study protocol was approved by the Institutional Review Board of the Eunice Kennedy Shriver National Institute of Child Health and Human Development.

For the current study, the analyses were restricted to participants who reported being licensed for independent, unsupervised driving; drove at least one day in the last 30 days, and provided valid responses for portable electronic device use in the last 30 days $(\mathrm{N}=1,243)$. There were no significant differences in age or gender between those who reported having a license to drive independently to those did not have a license.

\section{Dependent variables}

Seven behaviors that involved the use of portable electronic devices while driving were measured: On how many days in the last 30 days while driving have you (a) made or answered a call; (b) read or sent a text/message; (c) read or sent an email; (d) checked a website, or social network such as twitter or Facebook; (e) frequently changed music; (f) used an iPad, tablet or computer; and $(\mathrm{g})$ looked at directions, on a map, phone or navigation device?

To compare the findings of this study to the existing literature, secondary task engagement while driving was coded as occurring at least one day in the last 30 days vs. not at all during the last 30 days. A second measure of electronic device use while driving was calculated by dividing the number of days electronic devices were used while driving in the last 30 days, by the number of days a vehicle was driven in the last 30 days. This produced the percentage of days an electronic device was used, relative to the number of days driven.

\section{Independent variables}

Demographic Characteristics: Participants reported their age, gender, and race (White, African American, Latino, Asian, Hawaiian/Pacific Islander, or Native American), and ethnicity (Hispanic or Latino). Due to small sample sizes of some categories, race/ethnicity was reduced to four categories: White, African American, Hispanic, and Other race/ethnicity.

Family Affluence: This measure was estimated using the Family Affluence Scale which includes measures of the number of cars owned, computers owned, whether the student had his/her own bedroom, and the number of family vacations in the last 12 months for each household (Currie, 
Roberts et al. 2004). Students were then categorized as low, moderate and high affluence (Spriggs, Iannotti et al. 2007).

Rural/Urban: Participants' schools were ranked in the first wave of the study according to a seven level scale ranging from large central city to rural area. Those attending schools in a rural area were categorized as rural, and the remaining categories were classified as urban.

Driving exposure: Exposure was estimated using two self-reported items. The first measure asked: "On how many days in the last 30 days did you drive a motor vehicle?" A second measure required participants to estimate "On average, about how many miles did you drive each day you drove?" Responses greater than 150 miles per day were eliminated as outliers.

\section{Analysis}

Statistical analyses (e.g., cross-tabulation, Rao-Scott Chi-Square, and logistic regression) were performed using SAS 9.4. Features of complex survey design (i.e., stratification, clustering and longitudinal sampling weights) were taken into account in all procedures. Domain analysis, referring to the computation of statistics for subpopulations in addition to the computation of statistics for the entire study population, was used for describing the electronic device used while driving.

\section{RESULTS}

Among 2,177 participants at Wave 4, 64\% $(n=1,376)$ were licensed; among the 1,376 licensed drivers, $90 \%(n=1,243)$ were included in the analysis. The average age of respondents in the sample was 19.08 years (standard error $(\mathrm{SE})=.03$ ), and $42.75 \%$ of participants were male. On average, participants reported driving 21.55 of the previous 30 days $(\mathrm{SE}=0.58)$ and approximately 23.75 miles each day they drove $(\mathrm{SE}=0.67)$.

Among the participants who were licensed and drove a vehicle in the last 30 days, $82.84 \%$ reported engaging in some form of electronic device use while driving at least once in the last 30 days. Specifically, $71.13 \%$ made or answered a phone call, $64.84 \%$ read or sent a text message, $20.29 \%$ read or sent an email, $29.11 \%$ checked a website, $71.64 \%$ changed music, $12.80 \%$ used a tablet or computer and $52.64 \%$ looked at directions or a map (Table 1). 
Table 1. Prevalence of electronic device use while driving among young drivers at least once in last 30 days

\begin{tabular}{|l|r|r|r|r|r|}
\hline \multicolumn{1}{|c|}{ Electronic Device Use } & N (total) & $\begin{array}{c}\text { N (secondary } \\
\text { task) }\end{array}$ & \multicolumn{1}{c|}{$\begin{array}{c}\text { Weighted } \\
\text { Percentage }\end{array}$} & \multicolumn{2}{c|}{$95 \%$ Confidence Interval } \\
\hline Made/Answered Call & 1,243 & 833 & 71.13 & 65.59 & 76.66 \\
\hline Read/Sent Text & 1,243 & 769 & 64.84 & 58.97 & 70.70 \\
\hline Read/Sent Email & 1,243 & 254 & 20.29 & 16.98 & 23.60 \\
\hline Checked Website & 1,243 & 361 & 29.11 & 23.95 & 34.26 \\
\hline Changed Music & 1,243 & 874 & 71.64 & 66.34 & 76.94 \\
\hline Used Tablet/Computer & 1,243 & 182 & 12.80 & 10.01 & 15.58 \\
\hline Looked At Directions/Map & 1,243 & 629 & 52.64 & 47.19 & \\
\hline
\end{tabular}

Young drivers reported using electronic devices while driving on $19.06 \%$ of the days they drove (Table 2). Overall, the proportion of days an electronic device was used while driving was higher among African-Americans than White, Hispanic and other racial/ethnical groups. Participants who reported driving fewer miles per day used an electronic device on a higher proportion of days than those who reported driving more miles per day. However, there were no significant differences among participants according to these demographic and behavioral characteristics.

Table 2. Percentage of days engaging in electronic device use relative to days driven in the last 30 days

\begin{tabular}{|c|c|c|c|}
\hline & $\%$ & se & $95 \% \mathrm{CI}$ \\
\hline Total & 19.06 & 1.14 & {$[16.68-21.44]$} \\
\hline \multicolumn{4}{|l|}{ Gender } \\
\hline Male & 19.50 & 1.73 & {$[15.89-23.10]$} \\
\hline Female & 18.73 & 1.36 & {$[15.89-21.58]$} \\
\hline \multicolumn{4}{|l|}{ Race } \\
\hline White & 18.28 & 1.50 & {$[15.15-21.42]$} \\
\hline Hispanic & 17.91 & 1.73 & {$[14.30-21.52]$} \\
\hline African-American & 26.18 & 2.42 & {$[20.47-31.90]$} \\
\hline Other & 18.16 & 2.08 & {$[11.51-24.82]$} \\
\hline \multicolumn{4}{|l|}{ Family Affluence } \\
\hline Low & 17.52 & 2.07 & {$[13.20-21.83]$} \\
\hline Moderate & 19.60 & 1.36 & {$[16.77-22.43]$} \\
\hline High & 19.05 & 1.89 & {$[15.10-22.99]$} \\
\hline \multicolumn{4}{|l|}{ Rural/urban } \\
\hline Urban & 18.89 & 0.81 & {$[17.11-21.67]$} \\
\hline Rural & 19.27 & 1.88 & {$[14.68-23.86]$} \\
\hline \multicolumn{4}{|l|}{ Driving Exposure } \\
\hline Low $(<10$ miles $)$ & 20.10 & 2.03 & {$[15.83-24.37]$} \\
\hline Medium $(10-20$ miles $)$ & 19.68 & 1.60 & {$[16.34-23.01]$} \\
\hline High $(>20$ miles $)$ & 17.85 & 1.67 & {$[14.36-21.33]$} \\
\hline
\end{tabular}

Comparing the two measures of driving exposure used in the analysis, the number of days driven in the last 30 days was significantly associated with all portable electronic device use while driving. The likelihood of using any electronic device at least once in the last 30 days increased as the number of days driven increased. In contrast, the number of miles driven per day was not associated with portable electronic device use while driving (Table 3 ). 
Table 3. Logistic regression of electronic device use and driving exposure (At least once in the last 30 days)

\begin{tabular}{|l|c|c|c|c|c|c|}
\hline & \multicolumn{3}{|c|}{ Days driving in last 30 days } & \multicolumn{3}{c|}{$\begin{array}{c}\text { Driven miles per day } \\
\text { (capped to 150 miles) }\end{array}$} \\
\hline & OR & $\begin{array}{c}95 \% \\
\text { Confidence } \\
\text { Interval }\end{array}$ & $\mathrm{p}$ & OR & $\begin{array}{c}\text { 95\% Confidence } \\
\text { Interval }\end{array}$ & $\mathrm{p}$ \\
\hline Made/Answered Call & 1.07 & $1.05-1.09$ & $<.001$ & 1.01 & $0.99-1.02$ & 0.32 \\
\hline Read/Sent Text & 1.05 & $1.03-1.07$ & $<.001$ & 1.00 & $0.99-1.01$ & 0.71 \\
\hline Read/Sent Email & 1.05 & $1.03-1.08$ & $<.001$ & 1.00 & $1.00-1.01$ & 0.47 \\
\hline Checked Website & 1.05 & $1.03-1.07$ & $<.001$ & 1.01 & $1.00-1.02$ & 0.08 \\
\hline Changed Music & 1.05 & $1.03-1.07$ & $<.001$ & 1.00 & $0.99-1.02$ & 0.49 \\
\hline Used Tablet/Computer & 1.02 & $1.00-1.04$ & $<0.05$ & 1.01 & $0.99-1.02$ & 0.45 \\
\hline Looked At Directions/Map & 1.04 & $1.02-1.06$ & $<.001$ & 1.00 & $0.99-1.01$ & 0.89 \\
\hline
\end{tabular}

Table 4 presents a separate analysis of the significant associations between the demographic variables and electronic device use while driving. Males were more likely to use a tablet or computer at least once in the last 30 days while driving, teens from households with moderate and high family affluence were more likely to check a website at least once while driving in the last 30 days, and rural participants were less likely to look at directions or a map than urban participants.

Table 4. Associations between demographic variables and device use while driving (At least once in the last 30 days)

\begin{tabular}{|c|c|c|c|c|c|c|c|}
\hline Behavior & Demographic & $\mathrm{N}$ & $\mathrm{N}$ & Weighted & \multicolumn{2}{|c|}{$95 \% \mathrm{CI}$} & P for $\chi^{2}$ \\
\hline \multirow{2}{*}{ Used Tablet/Computer } & Female & 692 & 72.00 & 8.49 & 6.29 & 10.69 & $<.001$ \\
\hline & Male & 551 & 110.00 & 18.56 & 12.82 & 24.31 & \\
\hline \multirow{3}{*}{ Checked Website } & Low Family Affluence & 231 & 54.00 & 20.66 & 12.82 & 28.51 & $<.01$ \\
\hline & Moderate Family & 578 & 164.00 & 26.50 & 20.97 & 32.03 & \\
\hline & High Family Affluence & 337 & 116.00 & 37.34 & 27.10 & 47.59 & \\
\hline \multirow{3}{*}{$\begin{array}{c}\text { Looked At } \\
\text { Directions/Map }\end{array}$} & Low Family Affluence & 231 & 97.00 & 36.54 & 27.56 & 45.51 & $<.01$ \\
\hline & $\begin{array}{l}\text { Moderate Family } \\
\text { Affluence }\end{array}$ & 578 & 294.00 & 53.37 & 44.52 & 62.21 & \\
\hline & High Family Affluence & 337 & 186.00 & 59.39 & 50.67 & 68.11 & \\
\hline \multirow{2}{*}{$\begin{array}{c}\text { Looked At } \\
\text { Directions/Map }\end{array}$} & Urban & 749 & 399.00 & 56.57 & 50.35 & 62.79 & $<.05$ \\
\hline & Rural & 494 & 230.00 & 47.57 & 39.65 & 55.49 & \\
\hline
\end{tabular}

\section{DISCUSSION}

The findings of this study suggest portable electronic device use while driving is highly prevalent among teenage drivers in the United States. For behaviors such as talking and texting while driving, the prevalence estimates observed in this sample are similar to previously reported estimates. Hamilton and colleagues found that $57.8 \%$ of $16-17$ year olds reported talking on a cell phone at least once in the past 30 days (Hamilton, Arnold et al. 2013), and a Centers for Disease Control (CDC) survey found $64.7 \%$ of teenagers in the $9^{\text {th }}$ to $12^{\text {th }}$ grade had texted or emailed while driving on at least one day, in the last 30 days (Centers for Disease Control and 
Prevention 2014). Almost three quarters of respondents in this sample (71.13\%) reported making or receiving a call at least once in the last 30 days, and approximately two thirds $(64.84 \%)$ reported sending or receiving a text message. This study presents several refinements in the measurement of secondary task engagement. In addition to contributing to the growing body of literature on the prevalence of device use at least once in the last 30 days, this study also examined prevalence as the percentage of days a device was used relative to the number of days participants drove. Young drivers reported using an electronic device approximately one-fifth of the days they drove (19.06\%). Unlike the combined measure of texting and emailing used by the $\mathrm{CDC}$, this study separated these two behaviors and found the prevalence of emailing is significantly lower than texting while driving. While both actions may increase crash risk, they are distinct behaviors, and a combined prevalence estimate of both tasks may be misleading. This study also presents the first prevalence estimate of tablet use while driving, which $12.8 \%$ of participants reported doing in the previous 30 days.

Examining the association between electronic device use and two measures of driving exposure provides an additional contribution to the literature. As the number of self-reported miles increased, there was a (non-significant) trend towards decreasing electronic device use that occurred at least once in the last 30 days. In contrast, the number of days driven was positively significantly associated electronic device use while driving. It seems likely that as an individual spends more time in a vehicle, the likelihood of electronic device use while driving increases. Most individuals, particularly teens, are poorly equipped to report the number of miles they drive (Staplin, Gish et al. 2008). Therefore, driving exposure based on the number of days driven may be more reliable, and the association between days driven and electronic device use may be a more robust than the estimate based on the number of miles driven.

While self-reported measures are a widely used method to assess the prevalence of electronic device use while driving, it is a limitation of this study. Self-reported items may be influenced by the presence of laws that restrict these behaviors. Some behaviors that were included in these analyses, such as changing music and navigating may have used in-vehicle systems, and not required portable electronic device use. Assessment of rural or urban status for participants was based on data from the first wave of the study, conducted in 2008-2009, and may not reflect subjects' actual physical environment. Further, our analyses did not examine the association between portable electronic device use and crashes, which is the health outcome of interest.

\section{CONCLUSION}

Teenagers use cell phones, particularly text messaging, as a dominant form of communication, (Lenhart 2012). Prevalence estimates of teenage drivers' use of these devices are necessary to guide safety efforts. This study extends what is known about portable electronic device use while driving by providing a detailed description of several, previously unstudied high-risk electronic devise use behaviors. Separating behaviors (such as texting an emailing) and testing the association between electronic device use and two measures of driving exposure, present advances in measurement of secondary task engagement. Our findings indicate that secondary task engagement while driving among teenage drivers is highly prevalent; $82.8 \%$ reporting using any electronic device at least once in the past 30 days, and young drivers reported using electronic devices while driving on $19.06 \%$ of the days they drove. 


\section{ACKNOWLEDGMENT}

This research (contract number HHSN267200800009C) was supported in part by the Intramural Research Program of the Eunice Kennedy Shriver National Institute of Child Health and Human Development (NICHD), the National Heart, Lung and Blood Institute (NHLBI), the National Institute on Alcohol Abuse and Alcoholism (NIAAA), Maternal and Child Health Bureau (MCHB) of the Health Resources and Services Administration (HRSA), with supplemental support from the National Institute on Drug Abuse (NIDA).

\section{REFERENCES}

Centers for Disease Control and Prevention (2014). Youth Risk Behavior Surveillance - United States 2013, Morbidity and Mortality Weekly Report, Vol: 63, No. 4.

Currie, C., C. Roberts, A. Morgan, R. Smith, W. Settertobulte, O. Samdal and V. B. Rasmussen (2004). Young people's health in context. Health behaviour in school-aged children (HBSC) study: international report from the 2001/2002 survey (Rep. No. 4). Copenhagen, Denmark, World Health Organization.

Governors Highway Safety Association (2010). Curbing distracted driving: 2010 survey of state safety programs. . Washington DC.

Hamilton, B. C., L. S. Arnold and B. C. Tefft (2013). Distracted driving and perceptions of handfree technologies: Findings from the 2013 Traffic Safety Culture Index. Washington D.C., Automobile Association of America Foundation for Traffic Safety.

Klauer, S. G., F. Guo, B. G. Simons-Morton, M. C. Ouimet, S. E. Lee and T. A. Dingus (2014). "Distracted Driving and Risk of Road Crashes among Novice and Experienced Drivers." New England Journal of Medicine 370(1): 54-59.

Lenhart, A. (2012). Teens, Smartphones and Texting. Washington D.C., Pew Research Center. Madden, M. and L. Raine (2010). Adults and Cell Phone Distractions. Washington D.C., Pew Research Center.

O’Brien, N. P., A. H. Goodwin and R. D. Foss (2010). "Talking and texting among teenage drivers: a glass half empty or half full?" Traffic injury prevention 11(6): 549-554.

Spriggs, A. L., R. J. Iannotti, T. R. Nansel and D. L. Haynie (2007). "Adolescent Bullying Involvement and Perceived Family, Peer and School Relations: Commonalities and Differences Across Race/Ethnicity." Journal of Adolescent Health 41(283-293).

Staplin, L., K. W. Gish and J. Joyce (2008). "Low mileage bias' and related policy implications-A cautionary note." Accident Analysis \& Prevention 40(3): 1249-1252.

Tison, J., N. Chaudhary and L. Cosgrove (2011). National phone survey on distracted driving attitudes and behaviors. National Highway Traffic Safety Administration. Washington DC.

Young, K. L. and M. G. Lenne (2010). "Driver engagement in distracting activities and the strategies used to minimise risk." Safety Science 48(3): 326-332. 